\title{
Thermodynamic analysis of growth of iron oxide films by MOCVD using tris(t-butyl-3-oxo-butanoato)iron(III) as precursor
}

\author{
SUKANYA DHAR*, K SHALINI and S A SHIVASHANKAR \\ Materials Research Centre, Indian Institute of Science, Bangalore 560 012, India
}

MS received 8 January 2008; revised 9 April 2008

\begin{abstract}
Thermodynamic calculations, using the criterion of minimization of total Gibbs free energy of the system, have been carried out for the metalorganic chemical vapour deposition (MOCVD) process involving the $\beta$-ketoesterate complex of iron [tris(t-butyl-3-oxo-butanoato)iron(III) or Fe(tbob) $)_{3}$ ] and molecular oxygen. The calculations predict, under different CVD conditions such as temperature and pressure, the deposition of carbon-free pure $\mathrm{Fe}_{3} \mathrm{O}_{4}$, mixtures of different proportions of $\mathrm{Fe}_{3} \mathrm{O}_{4}$ and $\mathrm{Fe}_{2} \mathrm{O}_{3}$, and pure $\mathrm{Fe}_{2} \mathrm{O}_{3}$. The regimes of these thermodynamic CVD parameters required for the deposition of these pure and mixed phases have been depicted in a 'CVD phase stability diagram'. In attempts at verification of the thermodynamic calculations, it has been found by XRD and SEM analysis that, under different conditions, MOCVD results in the deposition of films comprising pure and mixed phases of iron oxide, with no carbonaceous impurities. This is consistent with the calculations.
\end{abstract}

Keywords. MOCVD; pure and mixed iron oxide films; CVD phase stability diagrams.

\section{Introduction}

Iron oxide thin films have found widespread application as materials for gas sensors, protecting pigments, magnetic recording media, and catalysis, because of their high thermal stability, hardness, and favourable magnetic properties (Mathur et al 2002). As one of the most powerful techniques suitable for the formation of stoichiometric and microstructured thin films (Park et al 2006), chemical vapour deposition has been employed for fabrication of iron oxide thin films from different precursors (Shalini et al 2003 and the references therein; Mathur et al 2006; Park et al 2006; Pflitsch et al 2006; Lee et al 2007). The overall motivation for the present work has been to conduct analytical studies to provide stability windows in the CVD process employing metalorganic precursors, corresponding to the experimental realization of specific iron oxide phases.

As CVD is by definition a chemical process, various process parameters and chemistry of the precursor affect the formation of a given phase, its microstructure, and related properties. Thermodynamic analysis of chemical reactions has been employed extensively to design and optimize chemical processes (engineering). Such analysis has also been occasionally applied to the development and understanding of CVD, assuming that equilibrium prevails in the process, which is applicable when the rate of deposition is low (Stringfellow 1989; Bernard et al 1999; Kang

*Author for correspondence (sukanya@mrc.iisc.ernet.in) et al 2000). For the CVD of transition metal oxides with multiple oxidation states, thermodynamic calculations can be employed to infer the deposition conditions required to obtain specific oxide phases. These conditions include the (substrate) temperature, the pressure in the CVD reactor, and the relative molar concentration of the reactants.

A $\beta$-ketoesterate complex, viz. tris(t-butyl-3-oxo-butanoato)iron(III), abbreviated as $\mathrm{Fe}(\mathrm{tbob})_{3}$, was used in the present study as precursor, because of the enhanced volatility caused by the oxygen atom in the terminal group of this subliming solid (molecular structure shown in figure 1). It is a natural precursor for the CVD of oxide films, because each metal-ion is bonded directly to six oxygenions in each molecule. It may be expected that complexes of this type, when used as precursor under different sets of CVD process parameters, may yield the metal or dif-

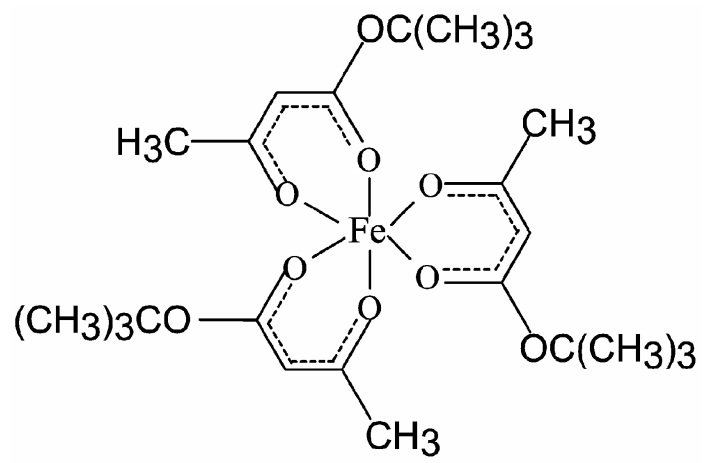

Figure 1. Molecular structure of the metalorganic complex, $\mathrm{Fe}(\mathrm{tbob})_{3}$. 
Table 1. Phases considered for the thermodynamic analysis of MOCVD in oxygen atmosphere.

\begin{tabular}{ll}
\hline Solid & $\mathrm{Fe}, \mathrm{Fe}_{0.945} \mathrm{O}, \mathrm{Fe}_{0.947} \mathrm{O}, \mathrm{FeO}, \mathrm{FeO}_{1 \cdot 056}, \mathrm{FeO}_{1 \cdot 5}, \mathrm{Fe}_{3} \mathrm{O}_{4}, \mathrm{Fe}_{2} \mathrm{O}_{3}, \mathrm{Fe}(\mathrm{OH})_{2}, \mathrm{Fe}(\mathrm{OH})_{3}$, \\
& $\mathrm{Fe}_{2} \mathrm{O}_{3} \cdot \mathrm{H}_{2} \mathrm{O}, \mathrm{FeO} . \mathrm{OH}, \mathrm{Fe}_{3} \mathrm{C}, \mathrm{FeCO}_{3}, \mathrm{C}$ \\
Gaseous & $\mathrm{CO}, \mathrm{CO}_{2}, \mathrm{H}_{2} \mathrm{O}, \mathrm{C}_{4} \mathrm{H}_{8}$ (2-methyl propene, or isobutene), $\mathrm{C}_{2} \mathrm{H}_{2} \mathrm{O}$ (ketene), $\mathrm{CH}_{3} \mathrm{CHO}$ \\
& (acetaldehyde), $\mathrm{HCOOH}$ (formic acid), and $\mathrm{CH}_{3} \mathrm{COOH}$ (acetic acid) \\
\hline
\end{tabular}

ferent oxides of the multivalent metal, or various combinations of these components with carbon, as observed in the case of copper (Ottosson and Carlsson 1996; Mukhopadhyay et al 2002a, b) and cobalt metalorganic complexes (Paranjape et al 2002; Mane and Shivashankar 2003; Apátiga and Castaño 2006).

Equilibrium compositions of the solid and gaseous species formed during the deposition process have been calculated for a relatively high flow rate of oxygen, as functions of several CVD parameters. This leads to the construction of 'CVD stability diagrams', which have been verified by carrying out experiments designed for the purpose. Thus, iron oxide films were deposited at different substrate temperatures $\left(T_{\text {sub }}\right)$, total reactor pressures $(P)$, and at various flow rates of oxygen $\left(F_{\text {oxy }}\right)$. The phase compositions and microstructure of the films deposited were studied using X-ray diffraction (XRD) and scanning electron microscopy (SEM), respectively.

\section{Procedure}

\subsection{Analytical}

The method of equilibrium calculations is based on the minimization of the Gibbs free energy of the system considered, satisfying the mass balance conditions (Eriksson 1971). The approach requires the identification of all the possible reactants and reaction products. The procedure for enumerating the gaseous species to be considered in the calculations, by consulting the mass spectrum of the precursor and employing 'chemical reasoning', is described in our earlier publications (Mukhopadhyay et al 2002a, b; Dhar et al 2008). For the CVD process with $\mathrm{Fe}(\mathrm{tbob})_{3}$ as precursor, every possible solid product was considered for the analytical study. These are listed in table 1, along with the possible gaseous products. Calculations were performed, as described earlier (Mukhopadhyay et al 2002a, b; Dhar et al 2008), to obtain the concentrations of the various possible solid and gaseous products of the MOCVD process, as functions of substrate temperature $\left(T_{\text {sub }}\right)$, total reactor pressure $(P)$, and the ratio of the molar flow rates of oxygen and the vapour of the metalorganic precursor $\left(\mathrm{O}_{2} / \mathrm{Pre}\right)$. The corresponding phase stability diagrams were also constructed.

\subsection{Experimental}

The iron complex was synthesized, purified, and characterized in house (Urs et al 2000). Iron oxide thin films were grown on glass substrates in a hot-wall, horizontal, low-pressure MOCVD reactor, in which the total pressure $(P)$, flow rates of carrier (argon) and reactant (oxygen) gases, substrate temperature $\left(T_{\text {sub }}\right)$, and the precursor vapourizer temperature $\left(T_{\mathrm{vap}}\right)$, could be controlled. While electronic mass flow controllers were used to regulate the flow of the gases, the average flow rate of the vapours of the metalorganic precursor was computed from the weight loss of the precursor during a deposition run, assuming the vapour to be a perfect gas. Further details of the CVD process are described elsewhere (Shalini et al 2003). The as-deposited films were characterized by X-ray diffraction (XRD) for the identification of crystalline phases, and scanning electron microscopy (SEM) for morphology.

\section{Results and discussion}

\subsection{Analytical}

As already noted, an important variable in thermodynamic calculations is the relative molar concentrations of the reactants, i.e. molar flow rates of oxygen, and the metalorganic complex, in the present case. While this molar ratio, $\mathrm{O}_{2} /$ Pre, may be varied over a wide range experimentally, there is an upper limit to the number of moles of oxygen that can be consumed by one mole of the precursor. This is the number of moles of oxygen required to oxidize all the constituent atomic species completely. This limit is 30 for $\mathrm{Fe}(\mathrm{tbob})_{3}$, based on the assumption of complete oxidation of $\mathrm{Fe}, \mathrm{C}$, and $\mathrm{H}$ to $\mathrm{Fe}_{2} \mathrm{O}_{3}, \mathrm{CO}_{2}$, and $\mathrm{H}_{2} \mathrm{O}$, respectively. The presence of oxygen beyond this limit does not affect the thermodynamic calculations, though, in the actual deposition process, this extra oxygen may change the hydrodynamics of the CVD system. The range of $\mathrm{O}_{2} /$ Pre ratios used in this analytical study is close to the upper limit, and the same range was employed in the experimental deposition process.

Figure 2 shows variations in the calculated equilibrium molar concentrations of various condensed phases, as functions of $\mathrm{O}_{2} /$ Pre, at $T_{\text {sub }}=$ (a) $350^{\circ} \mathrm{C}$ and (b) $500^{\circ} \mathrm{C}$, and $P=2$ Torr. All calculations have been carried out assuming that one mole of the precursor is consumed. (If the amount of precursor consumed is different, the numbers on the ordinate of figure 2 will be altered merely by a multiplication factor, the relative proportions of the compounds formed remaining the same). At $350^{\circ} \mathrm{C}$ (figure 2(a)), simultaneous deposition of $\mathrm{Fe}_{3} \mathrm{O}_{4}$ (magnetite) and carbon (on the substrate) is to be expected for lower ratios of $\mathrm{O}_{2} / \mathrm{Pre}$, accompanied by carbon monoxide, carbon 
dioxide, and water vapour in the gas phase. The amount of carbon in the deposit decreases with increasing $\mathrm{O}_{2} / \mathrm{Pre}$ ratio, and finally reduces to zero, resulting in pure $\mathrm{Fe}_{3} \mathrm{O}_{4}$ films on a suitable substrate. At $500^{\circ} \mathrm{C}$ (figure 2(b)), no carbon impurity is to be expected in the deposit of $\mathrm{Fe}_{3} \mathrm{O}_{4}$ that occurs in the range of $\mathrm{O}_{2} / \mathrm{Pre}$ ratios considered for the present study (26-32). At both these temperatures, as the $\mathrm{O}_{2} / \mathrm{Pre}$ ratio is increased further, the deposition of pure $\mathrm{Fe}_{3} \mathrm{O}_{4}$ is accompanied by the formation of a significantly rising amount of $\mathrm{CO}_{2}$ and a correspondingly diminishing amount of $\mathrm{CO}$. This continues till the number of moles of $\mathrm{CO}$ formed becomes zero, while that of $\mathrm{CO}_{2}$ reaches its maximum. When $\mathrm{O}_{2} /$ Pre is increased beyond this point, the additional oxygen contributes to the formation of increasing proportions of the higher oxide, $\mathrm{Fe}_{2} \mathrm{O}_{3}\left(\alpha-\mathrm{Fe}_{2} \mathrm{O}_{3}\right.$, or hematite), resulting in a mixture of $\mathrm{Fe}_{3} \mathrm{O}_{4}$ and $\mathrm{Fe}_{2} \mathrm{O}_{3}$ in the condensed phase. It is interesting to note that pure $\mathrm{Fe}_{2} \mathrm{O}_{3}$ is not expected in the solid phase until the com-
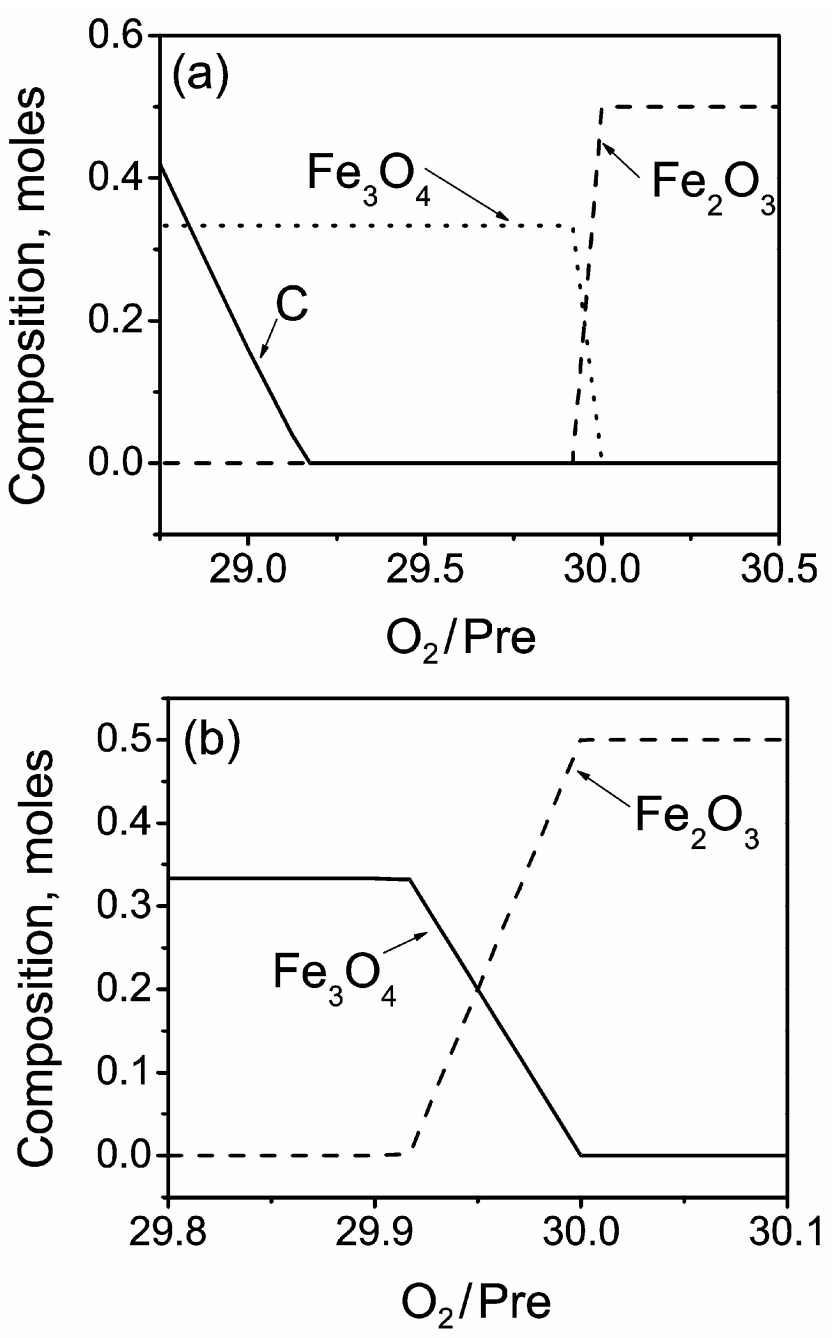

Figure 2. Variations in the calculated equilibrium molar concentrations of various condensed phases as a function of $\mathrm{O}_{2} / \mathrm{Pre}$ ratio, at $P=2$ Torr, and $T_{\text {sub }}=$ (a) $350^{\circ} \mathrm{C}$ and (b) $500^{\circ} \mathrm{C}$.

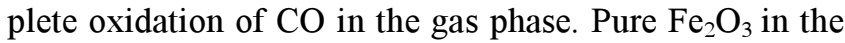
solid phase, and $\mathrm{CO}_{2}$ and $\mathrm{H}_{2} \mathrm{O}$ in the gas phase, are expected when the $\mathrm{O}_{2} /$ Pre ratio reaches its maximum value of 30 , beyond which there is no change in the relative proportion of these chemical species.

Results of similar calculations, performed as a function of $T_{\text {sub}}$, are summarized by constructing a CVD phasestability diagram to represent the formation of solid phases (figure 3). The boundary lines separating the regimes of pure $\mathrm{Fe}_{3} \mathrm{O}_{4}$, mixture of $\mathrm{Fe}_{3} \mathrm{O}_{4}$ and $\mathrm{Fe}_{2} \mathrm{O}_{3}$, and pure $\mathrm{Fe}_{2} \mathrm{O}_{3}$, are found to be essentially invariant with temperature. The composition of the mixture, resulting from a simultaneous deposition of the two oxides, is also essentially independent of temperature (the proportion of $\mathrm{Fe}_{2} \mathrm{O}_{3}$ in the mixture increases extremely slowly with temperature). However, the $\mathrm{O}_{2} /$ Pre ratio required for the elimination of carbon from the deposit decreases as the temperature is increased. That is, the process window for the deposition of carbon-free pure $\mathrm{Fe}_{3} \mathrm{O}_{4}$ films becomes wider at higher deposition temperatures. It is noteworthy that, although the CVD stability diagram is constructed for a process very different from the elemental $\mathrm{Fe}-\mathrm{O}$ system considered in 'traditional' binary phase diagrams, regions of stability exist in which more than one oxide phase is present, just as in the $\mathrm{Fe}-\mathrm{O}$ binary phase diagram.

Confusion may arise at a first glance of figure 3 because, without the gaseous species also being represented, the equilibrium CVD diagram looks like the familiar $\mathrm{Fe}-$ O binary system (Kingery et al 1976), to which it is not expected to be equivalent. The binary $\mathrm{Fe}-\mathrm{O}$ phase diagram represents analysis carried out for pairs of iron oxide systems, and each boundary line corresponds to a reaction of the type $\mathrm{Fe}_{3} \mathrm{O}_{4}+\mathrm{O}_{2} \rightarrow \mathrm{Fe}_{2} \mathrm{O}_{3}$, carried out at one atmospheric pressure. In the case of CVD, a particular precursor, with its own specific constraint of elemental composition and molecular structure, reacts with oxygen, typically at a

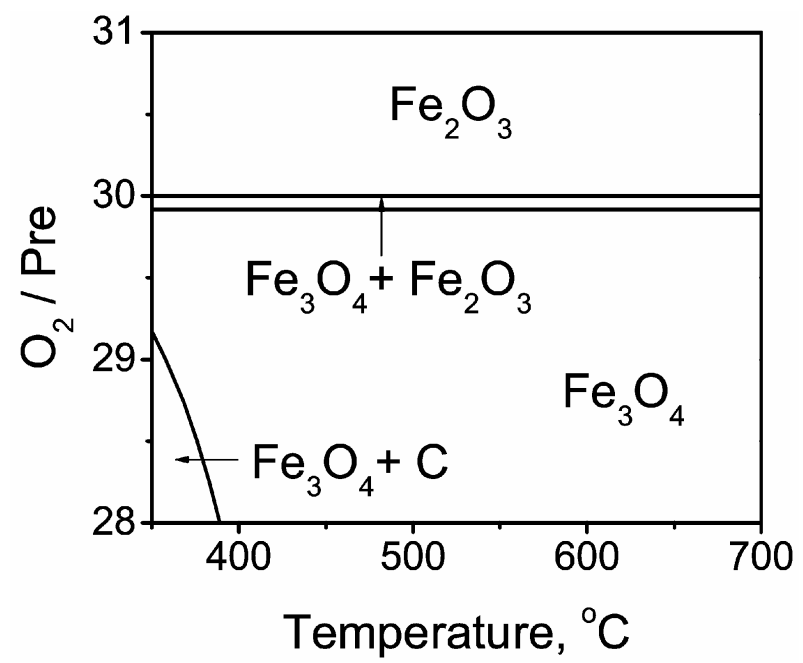

Figure 3. A 'CVD phase stability diagram' for solid phase formation, as a function of substrate temperature at $P=2$ Torr. 
reduced pressure. As the temperature and the $\mathrm{O}_{2} /$ Pre ratio are varied, reactions taking place along different chemical pathways to produce several condensed and gaseous products, are in equilibrium. The formation of the gaseous species, $\mathrm{CO}, \mathrm{CO}_{2}$, and $\mathrm{H}_{2} \mathrm{O}$, along with different oxides of iron, is an integral part of the MOCVD process. The boundaries in these CVD stability diagrams do not correspond to any particular reaction of the kind mentioned above regarding the binary $\mathrm{Fe}-\mathrm{O}$ phase diagram. The CVD stability diagram separates regions of different pure and mixed phases, and points to the formation of different phases in different parts of the parameter space. Nevertheless, this phase stability diagram is in qualitative agreement with the phase diagram presenting the stability ranges for the oxides of iron, determined experimentally by reactive vapour deposition method (Fujii et al 1989).

As a function of another CVD parameter, viz. the reactor pressure, the CVD stability diagram for solid phase formation (figure 4) again presents trends similar to those described above. The $\mathrm{O}_{2} /$ Pre ratios corresponding to the boundaries between pure $\mathrm{Fe}_{3} \mathrm{O}_{4}$, the mixed phase, and pure $\mathrm{Fe}_{2} \mathrm{O}_{3}$, are found to be constant, irrespective of pressure, while the region of formation of $\mathrm{Fe}_{3} \mathrm{O}_{4}$ accompanied by $\mathrm{C}$ widens, with increasing pressure. Compositions of the simultaneously deposited oxides are independent of pressure as well.

\subsection{Experimental}

MOCVD runs were carried out using process parameters spanning the range suggested by the thermodynamic analysis. The ranges of substrate temperature and total reactor pressure required for measurable deposition were consistent with thermodynamic analysis, while the $\mathrm{O}_{2} /$ Pre ratio had to be raised by different amounts above the

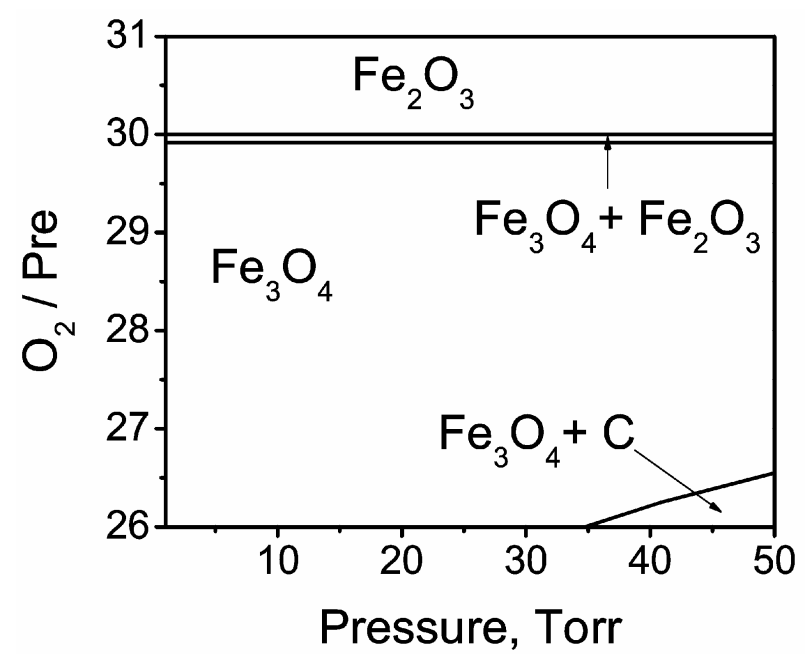

Figure 4. A 'CVD phase stability diagram' for solid phase formation, as a function of reactor pressure, at $T_{\mathrm{sub}}=500^{\circ} \mathrm{C}$. theoretically suggested values to obtain films of required compositions (which are different pure and mixed oxide phases, without much carbon impurity). Pure $\mathrm{Fe}_{3} \mathrm{O}_{4}$ was obtained for $F_{\text {oxy }}=50 \mathrm{sccm}$ and $100 \mathrm{sccm}$, which corresponds to experimental $\mathrm{O}_{2} /$ Pre ratios of 29.8 and 35.5 . However, $\mathrm{Fe}_{3} \mathrm{O}_{4}$ was deposited simultaneously with $\mathrm{Fe}_{2} \mathrm{O}_{3}$ at $F_{\text {oxy }}=150 \mathrm{sccm}$ (corresponding $\mathrm{O}_{2} /$ Pre $=41 \cdot 1$ ), and pure $\mathrm{Fe}_{2} \mathrm{O}_{3}$ was deposited at $F_{\text {oxy }}=200 \mathrm{sccm}$ (corresponding $\mathrm{O}_{2} /$ Pre $=47 \cdot 4$ ). This discrepancy between experiments and thermodynamic analysis in the required $\mathrm{O}_{2} /$ Pre ratio may be due to kinetic factors, such as the relative sticking probabilities of the molecules of oxygen and the precursor on the substrate (Kang et al 2000). It may also be due to progressive reduction in the residence time of the precursor as the total gas flow rate is raised holding the total reactor pressure constant at 2 Torr. In this case, the proportion of oxygen, which actually gets adsorbed on the substrate surface and reacts with the precursor during deposition, may be much smaller than the supplied quantity, thus accounting for the requirement of a much larger $\mathrm{O}_{2} /$ Pre ratio. The need for and the extent of higher $\mathrm{O}_{2} /$ Pre ratio (than that given by calculations) may also depend in part on hydrodynamics, i.e. the specific design of the reactor.

The dependence of iron oxide phase formation on the oxygen flow rate, for films grown at constant substrate temperature and total reactor pressure, is clearly seen in the XRD patterns (figure 5). The films do not show any

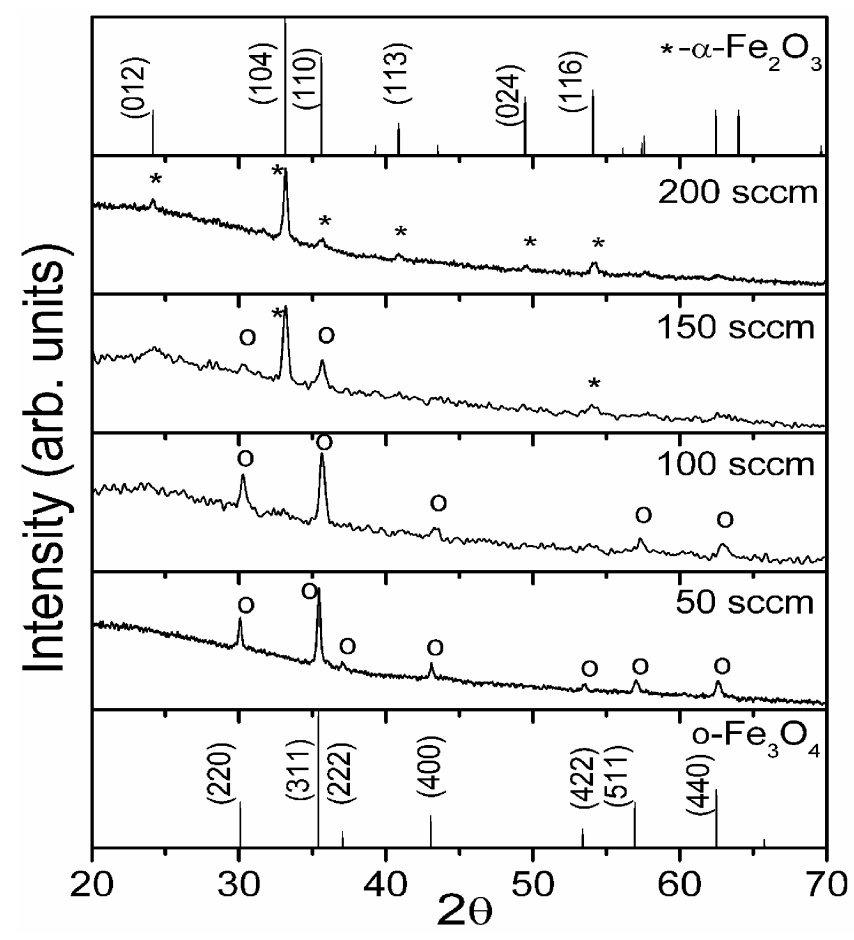

Figure 5. XRD patterns of iron oxide films deposited for oxygen flow rate $\left(F_{\text {oxy }}\right)$ ranging from $50 \mathrm{sccm}$ to $200 \mathrm{sccm}$, at $T_{\text {sub }}=500^{\circ} \mathrm{C}$ and $P=2$ Torr. 

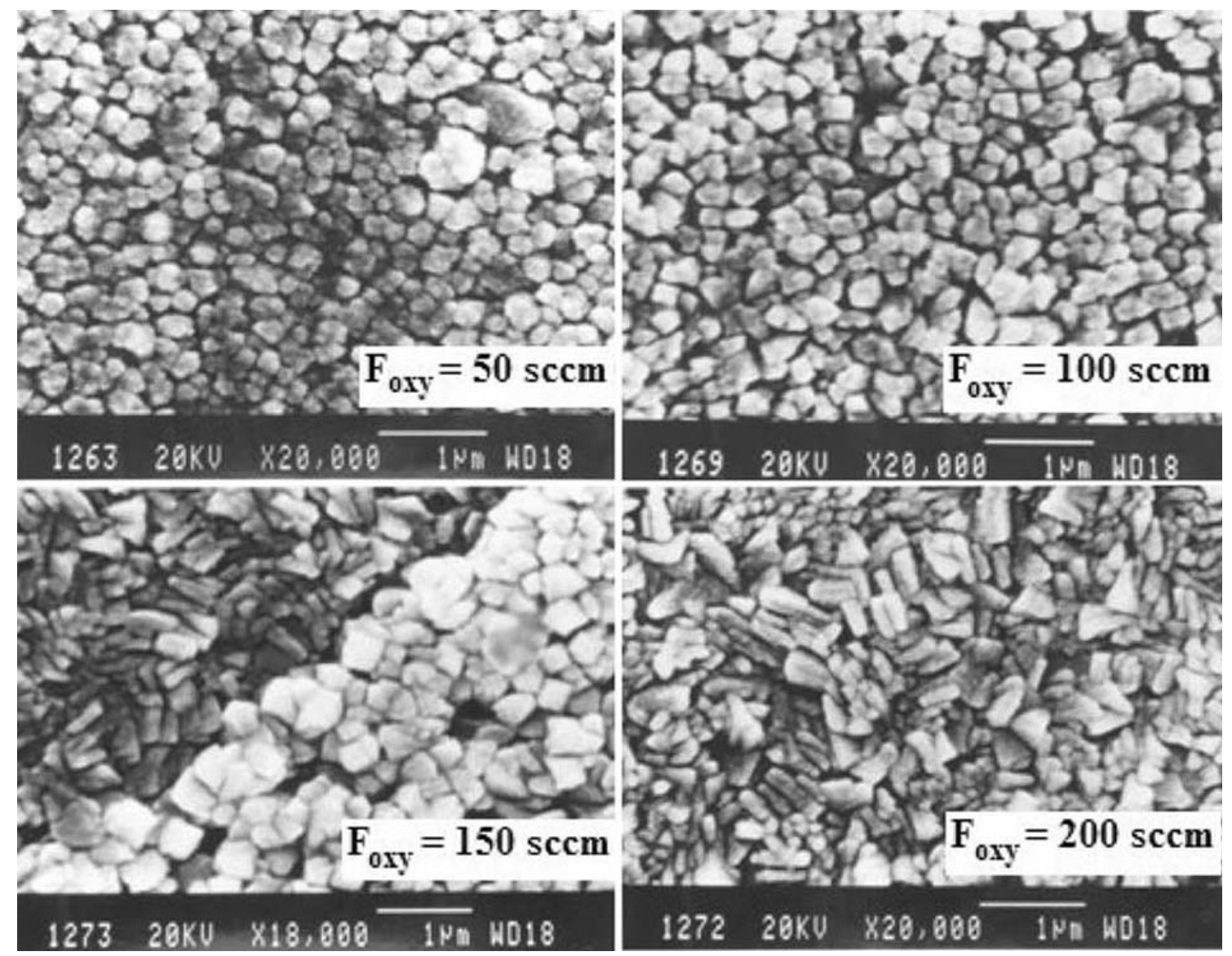

Figure 6. SEM micrographs corresponding to films presented in figure 5.

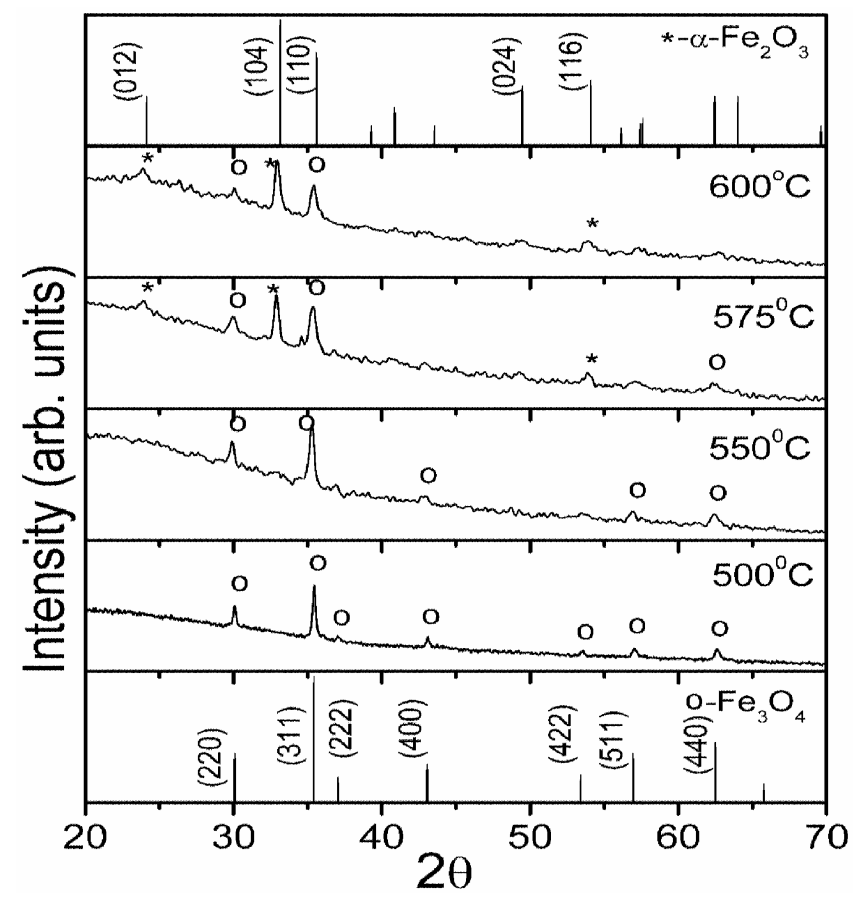

Figure 7. XRD patterns of iron oxide films deposited at temperatures in the range $500-600^{\circ} \mathrm{C}$, for $F_{\text {oxy }}=50 \mathrm{sccm}$ and $P=2$ Torr. crystallographic texture at the deposition (substrate) temperature of $500^{\circ} \mathrm{C}$. At $T_{\text {sub }}=500^{\circ} \mathrm{C}, P=2$ Torr, and oxygen flow rate $\left(F_{\text {oxy }}\right)$ ranging from $20-100 \mathrm{sccm}$, the only phase formed is $\mathrm{Fe}_{3} \mathrm{O}_{4}$. Peaks corresponding to $\alpha-\mathrm{Fe}_{2} \mathrm{O}_{3}$, along with those corresponding with $\mathrm{Fe}_{3} \mathrm{O}_{4}$, are present in the film deposited when the oxygen flow rate is increased to $150 \mathrm{sccm}$, implying simultaneous deposition of the two oxides at the higher $\mathrm{O}_{2} /$ Pre ratio employed. The intensity of the $\alpha-\mathrm{Fe}_{2} \mathrm{O}_{3}$ peaks, indicative of the amount of $\alpha-\mathrm{Fe}_{2} \mathrm{O}_{3}$ in the films, increases with increased flow rate of oxygen. Finally, when the oxygen flow rate is $200 \mathrm{sccm}$, pure, polycrystalline $\alpha-\mathrm{Fe}_{2} \mathrm{O}_{3}$ is formed, in accordance with the thermodynamic predictions. The changeover from $\mathrm{Fe}_{3} \mathrm{O}_{4}$ to $\alpha-\mathrm{Fe}_{2} \mathrm{O}_{3}$ phase is clearly illustrated by the differing morphology of the two phases, as seen by SEM (figure 6).

It is interesting to note that the XRD patterns follow a trend similar to that in figure 5, when iron oxide films were deposited at different temperatures in the range 500$600^{\circ} \mathrm{C}$, while reactor pressure and oxygen flow rate are held constant at 2 Torr and $20 \mathrm{sccm}$, respectively (figure 7). Pure $\mathrm{Fe}_{3} \mathrm{O}_{4}$ is formed up to $550^{\circ} \mathrm{C}$, and a combination of $\mathrm{Fe}_{3} \mathrm{O}_{4}$ and $\alpha-\mathrm{Fe}_{2} \mathrm{O}_{3}$ at higher temperatures. The corresponding SEM patterns also clearly indicate the existence of pure and mixed phases (Shalini et al 2003), displaying the distinct morphologies of the crystallites of $\mathrm{Fe}_{3} \mathrm{O}_{4}$ and 


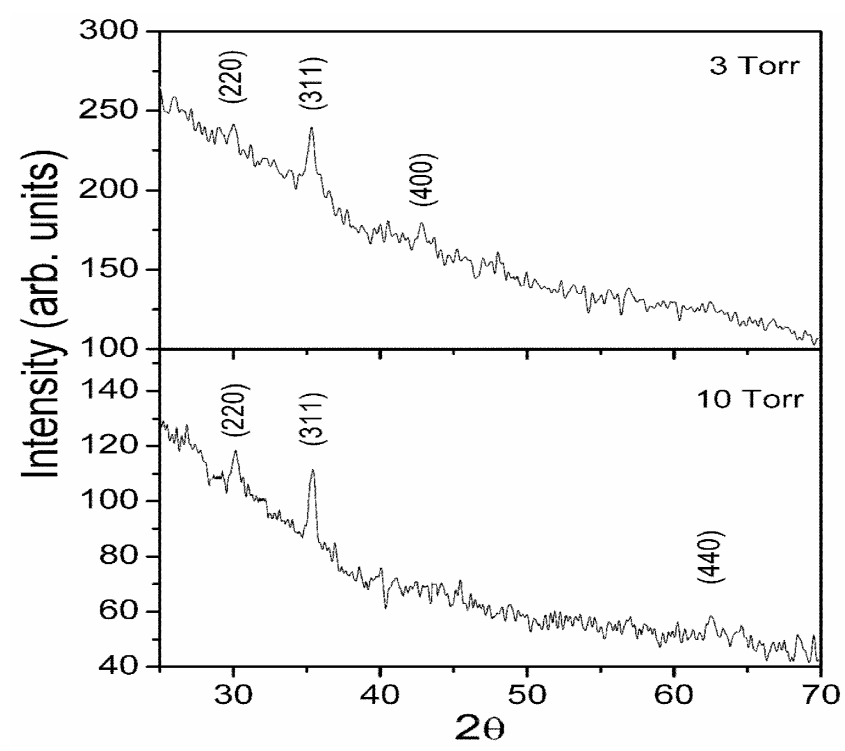

Figure 8. XRD patterns of $\mathrm{Fe}_{3} \mathrm{O}_{4}$ films deposited at different pressures, keeping the substrate at $500^{\circ} \mathrm{C}$ and the oxygen flow at $50 \mathrm{sccm}$.

$\alpha-\mathrm{Fe}_{2} \mathrm{O}_{3}$. The experimental results indicate a strong dependence of the phase composition of the films on temperature, in contrast with the theoretical calculations. It may be inferred that the actual $\mathrm{O}_{2} /$ Pre ratio at the growth surface increases with increasing temperature because of the dependence of the adsorption kinetics of the reactants on temperature (Kang et al 2000). Therefore, an increase in deposition temperature is similar to an effective increase in the $\mathrm{O}_{2} /$ Pre ratio, pointing to a qualitative agreement between the theoretical predictions and the experimental observations.

The characterization for the films grown at different pressures was restricted by the poor crystallinity and the falling growth rate of the films with increasing pressure (XRD patterns shown in figure 8). Increasing rates of gas phase reactions, which lead to a diminishing flux of reactants at the substrate surface, may cause the observed decline in the growth rate at higher reactor pressures, while simultaneous deposition of carbon (figure 4) may account for the poor crystallinity.

\section{Summary and conclusions}

Thermodynamic modeling of the MOCVD growth of iron oxide thin films, using the ketoesterate metalorganic complex, tris(t-butyl-3-oxo-butanoato)iron(III), as the precursor, was carried out. Concentrations of various solid and gaseous species expected to be formed under equilibrium conditions were computed as functions of CVD parameters, viz. substrate temperature, total reactor pressure, and the relative molar proportion of the metalorganic precursor and oxygen. The corresponding 'CVD phase stability diagrams' for the formation of the solid phases were constructed, indicating the process windows for the formation of different phases. Experimental results are in qualitative agreement with the thermodynamic calculations, specifically including the prediction of the simultaneous formation of hematite $\left(\alpha-\mathrm{Fe}_{2} \mathrm{O}_{3}\right)$ and magnetite $\left(\mathrm{Fe}_{3} \mathrm{O}_{4}\right)$ under certain deposition conditions. The quantitative discrepancy between calculated and experimental results may be attributed to the dependence of the actual $\mathrm{O}_{2} /$ Pre ratio at the growth surface on the deposition parameters. Thermodynamic calculations can, therefore, be useful in predicting trends in a MOCVD process involving metals with multiple oxidation states and, thus, be helpful in identifying possible impurities and/or undesired phases in the solid deposit.

\section{Acknowledgement}

One of the authors (SD) thanks the Department of Science and Technology, Government of India, for the grant of a research fellowship.

\section{References}

Apátiga L M and Castaño V M 2006 Thin Solid Films 496576

Bernard C, Pons C M, Blanquet E and Madar R 1999 MRS Bull. 2427

Dhar S, Dharmaprakash M S and Shivashankar S A 2008 Bull. Mater. Sci. 3167

Eriksson G 1971 Acta Chem. Scand. 25651

Fujii T, Takano M, Katano R and Bando Y 1989 J. Appl. Phys. 663168

Kang S Y, Choi K H, Lee S K, Hwang C S and Kim H J $2000 \mathrm{~J}$. Electrochem. Soc. 1471161

Kingery W D, Bowen H K and Uhlmann D R 1976 Introduction to ceramics (New York: John Wiley and Sons)

Lee J Y, Kang B C, Jung D Y and Boo J H 2007 J. Vac. Sci. Technol. B25 151

Mane A U and Shivashankar S A 2003 J. Crystal Growth 254 368

Mathur S, Veith M, Sivakov V, Shen H, Huch V, Hartmann U and Gao H B 2002 Chem. Vap. Depos. 8277

Mathur S, Sivakov V, Shen H, Barth S, Cavelius C, Nilsson A and Kuhn P 2006 Thin Solid Films 50288

Mukhopadhyay S, Shalini K, Lakshmi R, Devi A and Shivashankar S A 2002a Surf. Coat. Technol. 150205

Mukhopadhyay S, Shalini K, Devi A and Shivashankar S A 2002b Bull. Mater. Sci. 25391

Ottosson M and Carlsson J 1996 Surf. Coat. Technol. 78286

Paranjape M A, Mane A U, Raychaudhuri A K, Shalini K, Shivashankar S A and Chakravarty B R 2002 Thin Solid Films $\mathbf{4 1 3} 8$

Park S, Lim S and Choi H 2006 Chem. Mater. 185150

Pflitsch C, Viefhaus D, Bergmann U, Kravets V, Nienhaus H and Atakan B 2006 J. Electrochem. Soc. 153 C546

Shalini K, Subbanna G N, Chandrasekaran S and Shivashankar S A 2003 Thin Solid Films 42456

Stringfellow G B 1989 Organometallic vapour phase epitaxytheory and practice (New York: Academic Press) Ch. 3

Urs U K, Shalini K, Dharmaprakash M S, Shivashankar S A and Row T N G 2000 Acta Crystallogr. C56 e448 